\title{
Living and Labouring as a Music Writer
}

\author{
LAWSON FletcheR and RAMON LOBATO \\ SWINBURNE UNIVERSITY
}

\begin{abstract}
I attended gigs most weeks while studying at university. I was happy to remain a punter until around May, June 2007. A band called Cog played at The Tivoli. After the show, I read a review on FasterLouder.com.au which was poorly-written and factually incorrect-they mentioned a few songs that weren't played. It pissed me off. I thought: 'I can do better.' So I wrote a review of a show I saw that same weekend-Karnivool at The Zoo-and sent it to the Queensland editor of FasterLouder.com.au ... He liked it, and published it. I sent the same review to the editor of local street press Rave Magazine, who also liked it, and decided to take me on as an 'indie' CD reviewer; later, I started writing live reviews for Rave, too.
\end{abstract}

'Dale', a 23-year old freelance music writer

Like most music critics in Australia, Dale is an autodidact. His entry into a writing career started with ad hoc reviews for websites and local music magazines. Over 
time he built up a network of contacts, carefully honed his craft, and is now making a living by writing reviews and interviews for various magazines and websites. The money isn't good, but it's enough to live off-and Dale relishes the opportunity to influence how his readers understand and enjoy the culture around them and contribute to a wider conversation about music. Out of fandom and enthusiasm, a professional life has been constructed.

This is a common story in the micro-industry of music writing, and in the cultural industries more broadly. Most established critics and reviewers in Australia started out this way, parlaying their passion into a more professional engagement with popular culture. While an older generation of music journalists were formally trained via newspaper cadetships, most now begin with unsolicited pieces for streetpress and small magazines, or by online self-publishing. ${ }^{1}$ Music writing-like design, performance and many other creative fields-is in this sense a quasiprofession built on the back of amateur enthusiasm, unpaid labour and unofficial networks of referrals and recruiting.

What might an analysis of this quasi-profession contribute to our understanding of amateur economies more broadly? Among other things, we see an opportunity to enhance and refine some of the models of amateur cultural labour that underwrite current debate. Much of the growing body of work on this topic has involved a distanced theoretical critique of economic exploitation. This is a vital area of inquiry, to be sure, but as David Hesmondhalgh has recently argued: 'Discussions of amateur media need to pay attention to the meaning of work, and the quality of working life.'2 Hence it is necessary to focus simultaneously on the objective practices and subjective perspectives of writers-the occupational 'devices' and personal 'dispositions' which Paul du Gay argues are central to understanding any cultural occupation ${ }^{3}$-and how such devices and dispositions are dynamically linked.

In this article, we describe some of the different forms of value at work within the small-scale creative networks that make up the music writing economy. We approach this world from the point of view of the experiences and motivations of agents within it, with the aim of understanding how such a world is maintained and sustained despite its frail economic base. This amateur economy is not just an 
economy of money, but also one of pleasure, 'quality', influence, and credibility. In what follows, we show how these different kinds of currency interact.

Our analysis also seeks to fill a gap in the existing literature on music writing, which has largely focused on topics such as the historical emergence of rock criticism, constructions of authenticity and objectivity, and debates about the decline of critical voice. ${ }^{4}$ This article takes a different approach by analysing the lived experience of writers from the ground up rather than the top down. We describe their experiences and understandings of working in this field, first exploring the everyday rhythms of writing before considering how writers position themselves within industrial and creative networks. These interactions raise questions about how writers, as cultural intermediaries, accrue and manage different forms of capital when they lack recourse to professional credentials, institutions and pathways. ${ }^{5}$ Here we reveal some of the different ways in which writers locate themselves in this interstitial space and the different categories of value that attend to such positioning.

\section{-THE MUSIC WRITER WORKFORCE}

The community of music writers in Australia is made up of a wide array of people with varying backgrounds, ambitions and levels of investment in the notion of professional writing being an ideal occupation. Some are professional freelancers who piece together a living by juggling commissions from different publications; others write reviews and interviews on the side while studying or working in unrelated fields. As part of our research into music writing in Australia, we surveyed twenty writers and editors on their backgrounds, experiences and motivations, asking them how and why they came to music writing (and, sometimes, why they left). Data was gathered primarily through questionnaires and, in a few cases, short face-to-face or telephone interviews. There remains scope for ethnographic work that follows the fine grain of writers' practice, but our research concentrated on tracing career trajectories and understanding writers' experiences of and feelings about music writing. ${ }^{6}$ We sought out a range of writers at different points in their careers, concentrating on rock, pop and indie critics as these genres are where much of the activity is concentrated in the Australian music media. To give a sense of the kind of people who are active in this area, we offer here portraits of three 
individuals: a first-time writer, a semi-professional freelancer and a veteran writer with an international profile.

Anna, a Brisbane-based writer in her early twenties, contributes reviews and other content to a number of streetpapers and for a popular alternative music site. She got her start in music writing by setting up a blog with friends from university, after being inspired by classes she took on online publishing. This platform gave her a profile that she leveraged to gain other writing gigs. Anna is likely to spend fifteen to twenty hours a week writing, but most of this is unpaid. This is not a problem for her, as music writing is a 'passion' rather than a career: 'I just love music, and I love writing, so what else could I do? It's an obsession. ${ }^{77}$ As one of a new breed of writers who have bypassed streetpress for blogs, Anna shows how online self-publishing has now become the first stepping-stone into more established (but not necessarily better paying) publications. ${ }^{8}$

Eve is in a slightly later stage of her career as a music critic. She started out as a teenager by publishing her own zine, then moved on to streetpress and niche independent publications. Now, nearly ten years later, she writes irregularly for 'quality' outlets including art magazines and broadsheet newspapers in Australia, and is in a position to pick and choose her writing projects. Eve enjoys 'more speculative pieces' that examine music outside the confines of the weekly new release cycle, and she will only conduct interviews with artists face-to-face so she can get to know them properly. In this way, she has left behind the routinised CD and gig reviews that are the staple of aspiring writers. While she still writes gratis for her favourite publications, she has recently vowed to only write for a reasonable rate and has begun negotiating more equitable pay rates with editors. Her early aspiration to make a career out of writing is starting to wane: 'Unfortunately, I became an adult just at the moment when the idea of being a full-time music journalist disappeared off the radar.' Now, she spends less and less time on music reviews and more time on other parts of her creative practice, which includes cultural criticism, poetry and visual arts.

At the top tier of the industry we find David, a well-known freelancer who is among the highest paid music critics in Australia. A writer for well over two decades, David has worked for most of the major music magazines and newspapers in the country, and has also authored a number of books on the local industry. His 
reputation could conceivably secure him a salaried position, but David prefers to be a full-time freelancer, working on his own terms. He has a very strict schedule that amounts to around sixty hours a week. Having built up a reputation and extensive press contacts, he feels he is in a unique position to enlighten a wider cultural public and push for serious coverage of popular music in the arts sections of newspapers. He is also quite pragmatic about his writing practice, which he describes as a 'craft' requiring flexibility, efficiency and the ability to divorce personal tastes from your output. Contrary to the common doxa that music writers are simply 'enlightened fans', ${ }^{9}$ here relinquishing one's fandom and personal preferences in order to write engagingly about any music is the key: ${ }^{10}$

I work on assignment now-there are things that I'd like to do and I do get to do them, but I also value the idea that you can give me virtually anything, and I can write a good story on it. It's not about what I like. I write strong, contained, concise, informative [articles] about any actor, director, musician, producer, in any genre, and not anyone can make that switch. That's a skill of the craft.

As the comments above suggest, these three individuals have widely varying experiences, ambitions and expectations. Within these accounts, we can trace the outlines of several different understandings of value, career and meaning that circulate widely in the music writing community. Respondents such as Anna view their work as a means to express their love of a particular kind of music or as one part of their engagement with a particular music scene. They find much personal, but little or no financial, reward in working on an ad hoc 'hobby' basis. Others see music writing as a stepping-stone to other forms of writing or industry work, and thus approach it more instrumentally for the skills and contacts it provides. Veterans like David see their work as a professional craft rather than a labour of love.

In most of these positions no firm division is made between work and pleasure or, more broadly, between the economic, aesthetic and social functions of music writing. Everyday decisions-where to send reviews for publication, what tone to adopt in writing, and so on-are made within a force field of variables: the perceived quality of a publication, its rates of pay, its audience, its cachet and currency. Most writers we spoke to try to strike some kind of balance between writing for poorly 
paid niche publications and more mundane (but better-paying) writing assignments. This can mean working for free or doing extra voluntary tasks for publications you believe in, if they fulfil an important critical role. Chris, the editor of a niche alternative electronica magazine, described his publication as a 'labour of love, but one that is now spread across the labour of many writers around the country'. Holly mentioned that she sometimes forgoes her spot on the doorlist to a gig she is reviewing and pays the entry fee out of her own pocket, when 'it's a young or small band' that she feels deserves her financial support. Dale noted that some writing assignments actually cost him money, which he is happy to pay if the artist in question is someone he admires. Here he explains how he personally subsidised a feature he wrote on former Go-Betweens member Robert Forster:

I was paid $\$ 100$ for the article. I generally outsource my interview transcriptions. It cost me around $\$ 140$ for the transcription, so I was effectively operating at a loss, which is not something I tend to do. But it was such a great opportunity, to ask a hugely influential artist many questions about his whole career, that I was happy to wear the cost.

There is no doubt a degree of exploitation at work here, but responses such as these complicate the implicit tendency in creative labour debates to caricature these workers as dupes of a neoliberal system of exploitation. In music writing, cultural cachet and economic capital are often inversely related, in typically Bourdieusian fashion-yet the former, as enhanced 'profile', feeds into the latter over the longer term. ${ }^{11}$ Consider, for example, those niche publications that writers considered the most prestigious - such as electronica magazine Cyclic Defrost or respected indie website Pitchfork-and which are typically the lowest-paying. The high (sub)cultural capital garnered through writing for these publications, culturally rich but economically starved, tends to mediate the often negligible financial returns involved in such engagements. ${ }^{12}$ Hence, the issue here is not so much whether writers have agency, but rather how they knowingly negotiate precarious and piecemeal employment situations, including tactically donating labour when needed, to gain pleasure and payment doing what they love. 
- THE EVERYDAY RHYTHMS OF CREATIVE WORK

Having discussed some of the ways careers are built and maintained in this fieldand how the competing objectives of making money, taking pleasure in one's work, and accruing influence within particular scenes are juggled-let's now zoom in to consider how all this plays out at the level of the everyday. What does a music writer spend their time doing? What kinds of tasks, other than tapping away at a keyboard, make up this line of work? Where and how is the boundary between work and pleasure drawn?

In our research, writers mentioned a surprisingly diverse range of activities as being part of their 'work': going to gigs, parties and record launches; writing pitches; doing background research; repeatedly listening to review copies; conducting and transcribing artist interviews; corresponding with editors and chasing up invoices; and simply listening to music. Sometimes these tasks expand to take up an inordinate amount of time-for instance, it is not uncommon to spend five or more hours researching, interviewing, transcribing and writing an interview that pays only fifty dollars (or nothing at all). Writers also find their daytime work is reliant on participation in the night-time economy that is central to the industry, attending gigs and concerts for live reviews but also for the more intangible purpose of keeping tabs on local scenes. As Michael notes, working as a writer 'can be like having two jobs-one that pays, and you do from nine to five, and one that doesn't pay, that you do from five to midnight'.

As a burgeoning body of scholarship demonstrates, this experience is increasingly the norm for workers in creative industries. ${ }^{13}$ As Hamilton argues: "The uncertain conditions that have long characterised writers' experiences (irregular employment and remuneration, a dearth of professional organisations and a system that encourages competition) are now commonplace across the majority of employment sectors. ${ }^{14}$ The drivers of this casualisation process have been well established, and include labour deregulation and just-in-time industrial logics. But in the case of music writing, there are also a few more specific factors that should be taken into account, as they help explain the intensified mode of informal working that is prevalent in the industry.

Publishing and deadline cycles, which structure the rhythms of a writer's working life, make a 9-to-5 schedule difficult. Monthly magazines have long lead 
times, requiring careful planning and substantial pitches, whereas weekly streetpress magazines are more ephemeral and revolve instead around the cycles of local gigs and club nights. Online media have a different rhythm again, with the typical turnaround between submission and publication shrinking to days and writing work occurring at all times across the week in order to fill daily content quotas. Even more speeded-up are self-published music blogs, which repost material from press releases within minutes or hours. ${ }^{15}$ These widely varying publishing cycles make it difficult for music writers to maintain a full-time job and manage their finances, as opportunities for work and paycheques are wildly fluctuating. Adrian remarks:

As a freelancer, my income is inconsistent. Some weeks are good, where I receive lots of commissions and pitches are approved; others, I'm ignored, as magazine editorial staff go to ground to meet their monthly deadline, and I'm left to work on my pitches and think of other ways to make money.

Other writers referred to excruciating delays in receiving payments, which sometimes meant having to chase up publications months later for back pay. Obviously, a high degree of flexibility is essential here, but it can be both a curse and a blessing. Take for example Rick, who, after finding he could not secure a salaried writing position, now freelances for ten different publications, from music monthlies to obscure online entertainment guides. As the parent of a young child, he likes the flexibility of working from home and to his own schedule. But despite maintaining a disciplined daily routine, he still feels his livelihood is very precarious. "The reason I write for so many places is so I can cobble it together into a respectable income', he comments. 'It's very hard to budget, because I make drastically different amounts of money each month, though some things are steadier than others.'

It is tempting to decry these work practices as the exploitative dynamics of neoliberal creative sectors, which lock creative workers into a dead-end logic of lowwage labour disguised as flexibility. Certainly there are elements of exploitation here, and the line between work and pleasure is so faint as to be invisible. But it would be premature to apply in any general way the same kind of critique that is extended to other sectors of the 'cognitariat' class. After all, the capacity to have fun at work is unevenly distributed and highly valued. Drinking beer and watching a band at a pub while chatting with other fans or industry workers has an 
instrumental function in that it accrues the kind of cultural capital that is essential for music writers to do their jobs well, but it is not equivalent to the kind of labour being performed by, say, the cleaners or the security staff. Furthermore, the nonmonetary 'value' of writing work comes in many different forms, both tangible (free tickets, CDs, drink cards, sometimes even paid overseas trips) and intangible (connecting with audiences, having influence in a scene, participating in critical debate). ${ }^{16}$ Opportunistic publications certainly capitalise on writers' enthusiasm and our interviewees were keenly aware of this, and of the wider inequalities and uncertainties characterising their chosen field. Hence questions of free labour and exploitation cannot be easily isolated from questions of meaning, value, pleasure and privilege.

\section{—MANAGING PROXIMITY AND DISTANCE IN MUSIC INDUSTRIES}

Here, we turn to the forms of association-the relational positions music writers take up towards those around them-that characterise music writing. Writers function as content producers, but they are also cultural intermediaries involved in representing artists and music businesses to a wider reading and listening public. As such, their roles are characterised by varying relationships with other agents in this creative network: artists, readers, editors, publicists, fellow writers. How these relationships are configured and prioritised determine a writer's position within this network.

Some writers see themselves as part of a music industry made up of record labels, publicists, touring and management companies. Others feel that their obligation is first and foremost to a particular musical scene and to the fans, artists and enthusiasts who constitute it. Many writers oscillate between these two poles of identification. In all cases, however, tacit ideas about authenticity, autonomy and ethics shape the way these networks operate.

Perhaps the most important people in a writer's network are commissioning editors, responsible for recruiting, mentoring, editing, copy-editing and organising payment. Editors are typically a writer's sole point of contact with a publication, but at small magazines editors are the publication - they are frequently the only fulltime employees and may write a substantial amount of the content as well. All decisions, work and correspondence is routed through the editor, who has to 
embody the functions and values of their publication itself. (When we asked the editor of one website whether it has a 'house style', he remarked: 'Yeah there is, but it's in my head.') Furthermore, it is common knowledge that editors are just as often as poorly paid and overworked as the writers they manage-something which complicates the question of determinacy in creative labour critiques, as the agents of exploitation are themselves exploited in a similar way.

Given the intimate nature of music networks, writers are part of an insider culture and must also maintain good relationships with artists-and those who control access to them. Writers typically have only limited, highly formalised contact with more established musicians, whose busy touring and promotional commitments are overseen by managers and publicists, often in the form of the ubiquitous 'fifteen-minute phoner': a short telephone interview slotted between that of scores of other journalists also writing features plugging the artists' upcoming tour or release. Our writers spoke of the constraints and difficulties this format placed on them:

One of the worst things is how formulaic it can become. Writing about music, and particularly when you start writing about artists who are well known-and therefore you only get access to them when they're about to release an album or tour-is all about the album/tour they're trying to promote.

Certainly, the deep immersion reporting associated with magazines like Rolling Stone-and mythologised in movies like Cameron Crowe's Almost Famous-is virtually unheard of today. Many of our writers expressed frustration at the overwhelmingly promotional nature of interviews. However, we also found that writers can enjoy more generous, informal contact with emerging artists in smaller local scenes to which they often also belong, to the extent that they may even socialise with and work alongside them. Editors have different policies regarding this proximity-in some cases they appeal to the residues of a phantasmatic journalistic ethics of objectivity and try to avoid conflicts of interest around writers reviewing the work of people they know. But in some niche publications, editors valued writers more for the close contact they maintain with artists. The editor of a respected small-circulation electronica magazine put it this way: 
We expect an understanding that [our magazine] is not like writing for the street press where everything is advertorial. We want strong narratives and coverage of artists and scenes that aren't covered elsewhere-and in a depth that isn't possible in other publications. As far as objectivity goes, we also understand that many of the best stories come from people who are deeply involved and connected within particular subcultures and scenes and thus will tend to be heavily subjective.

As these various comments indicate, music writing involves both close and distanced relationships to artists, and the representational role writers play as cultural intermediaries gradually shifts along with this, frustrating some writers as they move from being supporters and intimate critics to promotional vessels for more established artists.

Publicists and marketing personnel are also key nodes in the music writer's network. As Keith Negus notes, the writer and the publicist are locked in a mutually dependent relationship, with the publicist relying on the writer to cover the artists and labels they represent, and the writer needing the publicist to gain access to these artists. ${ }^{17}$ Writers have long been studied as 'gatekeepers' of popular music, but it is publicists who precede them and who really fill this role; they hold the keys to resources (artists, review copies, key information), but also to perks such as guest spots, drink cards and parties. ${ }^{18}$ Freelancers and bloggers eager to maintain an edge over their competition must establish a close relationship with publicists, relying on them to arrange interviews and recordings in lieu of editors, or to provide news stories and exclusive MP3s for blog posts.

All writers acknowledged the importance of publicists, but our respondents displayed a great deal of antagonism towards the profession. Almost all believed publicists had a deleterious effect on the quality of music writing, even as they denied being personally affected. Criticisms centred around how publicists 'micromanage' the terms of interviews, influence who gets what kind of coverage and pressure writers to hedge their judgements or produce laudatory editorial in fear of offending those who hold the keys to further work:

A lot of readers dealing with the contemporary media constellation can't tell the difference between a 'copy, paste, scramble' of a press kit, and an article that has taken time and thought to put together. 
There's nothing worse than a critic who 'umms' and 'ahhs' and can't decide whether they like something. Or worse: if they're lying to their readers, or masking their true feelings because they don't want to offend the band, manager, publicist, label, or whoever.

Interestingly, some bloggers and niche writers try to disintermediate the publicist as much as possible, going straight to the source. Twitter, Facebook and email have made this task much easier than it used to be:

I rarely deal with publicists these days as most of the artists we cover are too small to have them and the labels we deal with are very low-key and self-maintained. It's so much easier going directly through the artist than the often unnecessary bureaucracy of the PR chain...

The best thing about blogging is the way it's brought artists, bloggers and readers closer together. There's less distro, less promo. If [publicists] block me, I just email the artist and ask them directly for a promo copy. Mostly they're all too happy to give me one...

Despite this widespread cynicism about publicists and publicity we found that many writers are just as likely to be writing promotional materials as using them. A number of people we spoke to mentioned making money on the side by producing promotional 'one sheets' that go out along with review copies of new releases, providing factual information (release dates, track listings and so on) but also complimentary descriptions of the record for reviewers to adopt. Dale, who stopped managing a band because of a perceived conflict of interest with his writing practice, didn't have the same qualms about writing one sheets. 'I treat that as any other assignment,' he commented, 'not as anything related to PR or publicity.'

Writers also have varying relations with-and images of-their readers. As has been widely noted, after the internet writers are no longer privileged mediators or 'gatekeepers': people can easily sample music online without relying on music magazines to describe and appraise new releases for them. ${ }^{19}$ The perceived loss of this opinion-shaping function leaves a void in the writer's identity, which some fill with new concepts of their work and obligations to readers. Perhaps this is one of the reasons that so many of the people we spoke to had a fairly amorphous view of who their audience might be or whether they may have any influence on them. Maguire and Matthews' suggestion that cultural intermediaries fulfil a 'broadly 
pedagogic function, shaping the perceptions and preferences of consumers in order to mobilize their actions along desired routes', was contradicted by the writers we spoke to, who held far more circumspect views of their influence. ${ }^{20}$

Indeed, what emerged from our research was a more complex image of audience agency. Many writers see themselves in an additive role-adding value and pleasure to readers who already have wide musical knowledge and certain tastes, turning people onto new music they may otherwise have missed-rather than as gatekeepers who shape (and also obstruct) the tastes of others in a zero-sum fashion. They feel that their legitimacy comes from filtering or curating an increasingly expansive musical universe. As Eve put it, 'the people being written about are often the ones reading', and the rest of their readership are generally already passionate fans. Thus, the writer's role is about advocacy and furthering a specific discourse within a 'public of equals, ${ }^{21}$ rather than critical gatekeeping in the conventional sense.

Having mapped out some of the relationships that constitute a writer's working life, we now consider an important internal dynamic within them: gender disparity. Almost half our sample of writers were women, but this composition is not reflected in the broader community of Australian music writers, which remains maledominated. $^{22}$ This point is important to stress given what Negus rightly describes as the 'assumptions about the pluralism, fluidity of movement [and] apparent openness' in media and creative occupations. As Negus argues, 'we need to ask more questions here about who is admitted or excluded, how this occurs and how it might vary across different arts and media industries. ${ }^{23}$ Indeed, the informal and closeknit nature of the creative networks we outlined above make it even more difficult for women to secure work, especially given that entry into writing positions is often gained on the basis of 'who you know' networking within a circle of (mostly) male commissioning editors. As Holly mentioned:

The editor of one large and very well known publication has never replied to a single pitch I've sent him, and I know this is the case for other female writers too. My boyfriend, however, has never had that problem, nor have many other male writers I know. This is not due to the quality of my pitches, because even if the answer is a no, the male writers I know still get the courtesy of that reply. 
Many of the spaces in which aspiring and working writers congregate, network and work, such as record stores, pubs and clubs, revolve around male camaraderie, performative trivia-harvesting and subcultural authority. In these spaces it can be difficult for female writers to enter a scene and develop contacts. ${ }^{24} \mathrm{~A}$ further factor in play is how discourse can reproduce and maintain structured systems of inequality ${ }^{25}$ - or, in Eve's words, how the preferences of 'middle-class white boys' form a critical consensus around which taste hierarchies are established and alternative perspectives are sidelined, sustaining the male-dominance of writing. ${ }^{26}$ This bias is underlined by dominant representations of women in music culture merely as desirable stars or ignorant, hysterical fans rather than experts. This has pernicious effects on expectations around women's participation. Chelsea commented that 'on dozens of occasions it was assumed I was just some girlfriend or groupie until I introduced myself'.

A number of our interviewees were less reflective on this topic, arguing that gender imbalance was simply a natural outgrowth of more men being interested in writing or playing in bands than women. In a milieu in which not only the right taste but also the social qualifications emerging from networks and friendships are key aspects to gaining work, the reproduction of exclusion becomes even more implicit, and thus harder to challenge, than more overt forms of discrimination. This is in line with other forms of retraditionalisation in new creative sectors, which often promote themselves as having outgrown entrenched patterns of exclusion and rigidity. ${ }^{27}$ Workers in these sectors may blur conventional divisions between work and leisure, or play shifting and multiple roles within creative networks, but as Negus notes they often use 'their access to the cultural industries to maintain a series of rather more traditional and enduring boundaries, social divisions and hierarchies'. ${ }^{28}$

\section{-BETWEEN SCENE AND INDUSTRY}

Having explored the biographies, experiences and working practices of music writers in Australia, we conclude by drawing together the common threads that emerged throughout this discussion with a more pointed conceptualisation of the music writer as a particular kind of cultural intermediary. Earlier we made a distinction between two different kinds of writers: the well-connected, full-time 
generalist whose primary site of identification is the broader music industry, and the part-time, specialist writer whose adherence is to smaller, niche publications or blogs deeply embedded in particular music scenes. We have discussed the 'protoprofessionalisation' strategies of the former elsewhere $;^{29}$ here we concentrate on the latter, and on the unique ways in which they trade in different forms of capital.

The primary site of identification for this second group of writers is the music scene and the niche publications that support it. Defined by Bennett and Peterson as 'contexts in which clusters of producers, musicians, and fans collectively share their common musical tastes and collectively distinguish themselves from others', scenes cohere around specific genres and social and geographic spaces, maintaining their own rituals and rules of participation and measures of authenticity and legitimacy. ${ }^{30}$ Importantly, scenes consist not only of musicians and fans but also a whole range of cultural intermediaries from promoters, record labels and venue owners, to photographers and, of course, writers. In many ways, these scenes are the 'soft infrastructure' for forms of cultural production that provide an alternative to the multinational music industry, in which large firms produce music for mass markets. ${ }^{31}$ Instead, scenes are localised creative networks based on the efforts of 'small collectives, fans turned entrepreneurs, and volunteer labour' offering their participants informal, entrepreneurial means of making a living as more conventional pathways to vocational and economic success diminish. ${ }^{32}$ These closely linked participants blur distinctions between producer and consumer, amateur and professional, and there is a great deal of traffic between these various subject positions.

A good example of these dynamics is Mess+Noise, which until 2007 was a limited-run magazine dedicated to Melbourne's indie music community. Since then it has become an online publication with a broader, national focus. Eve, who wrote for Mess+Noise in its early days, describes it as 'the only situation in which I've had a very concrete idea of an audience or readership', noting that writers, musicians and readers were in close proximity and often overlapped:

The independent music community in Australia is really very small and you get to know everyone quite quickly-the writers were going to the same shows together and the people that were reading the magazine were the same people who were being written about. This gave the publication a 
real sense of purpose that's impossible to manufacture. It still does this as

an online publication, which is one reason why its readership is so loyal.

Mess+Noise writers share a common goal of speaking to and representing a local community of musicians and listeners. Music writing is thus part of the 'support' or intermediary activity that sustains and represents a scene to itself and to the wider musical public-producing a critical discourse and language that helps other participants define themselves, often against a vague idea of the mainstream. As Thornton notes, niche media can 'baptize scenes and generate the selfconsciousness required to maintain cultural distinctions ${ }^{33}{ }^{33}$ The position of writers within these scenes also testifies to the emerging forms of organising creativity and labour within small-scale creative networks in which the circulation of economic capital is low. As we noted earlier, many writers are willing to work for free for valued publications which function as taste-makers within particular scenes. Moreover, writers themselves benefit from their participation in these scenes in various ways. In particular, such participation allows these writers to rationalise their work on the basis of social, cultural and creative rather than monetary values.

Notions of non-economic or extra-economic contribution are, therefore, extremely important, a dynamic we have underlined throughout this article. Earlier, we explored how commitment to different publications is apportioned according to highly nuanced categories of cultural and monetary value and how, despite often devoting more time to it than is financially rational, writers derive different kinds of utility and fulfilment from their time spent listening, networking and writing. What, then, are the implications of this dynamic for debates around cultural labour in amateur economies?

For one, it suggests ongoing studies of creative labour may need to consider the highly specific notions of value at work within small-scale creative worlds. These fields operate on the basis of distinct social and cultural currencies that otherwise remain hidden when viewed from an overly structural perspective. This is particularly the case for amateur intermediaries such as music writers, for their representation of a creative milieu allows them to reconcile their position as underpaid workers whose cultural production is not specifically 'artistic'. The point here is not to contradict wider arguments around the exploitative conditions many cultural workers find themselves in; rather, it is to acknowledge that for many 
writers, who achieve a limited agency nonetheless, this is very much a consensual and pleasurable form of labour.

Indeed, the most striking feature of this cultural economy is that social constructions of taste and artistic value are absolutely central to the identities of amateur writers, as much as the professional markers of pay and secure employment. On this point, our findings simply underscore the fact, which is nonetheless obscured in current creative labour debates, that people engage in creative activities for a host of non-monetary reasons. The notion of the amateur as someone motivated by love rather than a pay cheque stands here, but is complicated by the different forms of value they also trade in. In the quasi-profession of music writing, cultural, social and economic capital are scrambled into ever-new configurations.

Lawson Fletcher is a postgraduate student at the Swinburne Institute for Social Research, whose research centres on the aesthetics and textures of cultural technologies. His doctoral thesis examines the domestic afterlives of residual media in the context of obsolescence and nostalgia.

Ramon Lobato is a postdoctoral research fellow at ARC Centre of Excellence for Creative Industries and Innovation at the Swinburne Institute for Social Research. His research explores the dynamics of informal media and cultural economies. He is the author of Shadow Economies of Cinema: Mapping Informal Film Distribution (2012) and co-editor of Amateur Media: Social, Cultural and Legal Perspectives (2012). 
-NOTES

1 Metropolitan streetpress magazines have long been a central feature of the Australian music scene. Since 1976, when Brisbane's Time Off was first published, streetpress has been providing a groundlevel entry point into the industry for young, aspiring writers. Being solely advertiser-funded, the razor-thin operating budgets and sizeable copy demands of streetpress papers ensure low barriers to entry and even lower pay rates. Their penetration across Australia is uniquely high —with at least one title operating in every capital city bar Hobart and Darwin — but streetpress are also present in cities across the United States and Europe, maintaining, as Brennan argues, a local sense of place within an increasingly global media culture. See Marc Brennan, 'This Place Rocks! The Brisbane Street Press, Local Culture, Identity and Economy', Continuum, vol. 21, no. 3, 2007, pp. 433-44; Sean Sennett and Simon Groth, Off the Record: 25 Years of Music Streetpress, University of Queensland Press, Brisbane, 2010. The quality of the Australian streetpress is much debated and was famously ridiculed by expatriate music writer Everett True in a column for the Guardian ('The Exiled Outbursts of Our Man in Australia', the Guardian, 6 August 2008).

2 David Hesmondhalgh, 'Have Amateur Media Enhanced the Possibilities for Good Media Work?' in Amateur Media: Social, Cultural and Legal Perspectives, ed. Dan Hunter, Ramon Lobato, Megan Richardson and Julian Thomas, Routledge, London and New York, 2012, pp. 137-49.

3 Paul du Gay, 'Devices and Dispositions: Promoting Consumption', Consumption, Markets and Culture, vol. 7, 2004, pp. 99-105.

${ }^{4}$ On historical emergence, see Ulf Lindberg, Gestur Guðmundsson, Morten Michelsen and Hans Weisenthaunet, Rock Criticism from the Beginning: Amusers, Bruisers, and Cool-Headed Cruisers, Peter Lang, New York, 2005. On authenticity, see Hans Weisethaunet and Ulf Lindberg, 'Authenticity Revisited: The Rock Critic and the Changing Real', Popular Music and Society, vol. 33, no. 4, 2010, pp. 465-85; Devon Powers, “'Bye Bye Rock”: On the Possibility of an Ethics of Rock Criticism', Journalism Studies, vol. 10, no. 3, 2009, pp. 322-36. On decline, see Eamonn Forde, 'From Polyglottism to Branding: On the Decline of Personality Journalism in the British Music Press', Journalism, vol. 2, no. 1, 2001, pp. 23-43; Jacob Levenson, 'Why John Lennon Matters: The Case for Professional Pop-Music Critics in an Amateur Age', Columbia Journalism Review, July/August 2009, pp. 54-8.

${ }^{5}$ Current scholarship on cultural intermediaries has launched off Bourdieu's original formulation of those cultural workers involved in 'presentation and representation [of] symbolic goods and services', which he saw as central to the rise of the petite bourgeoisie. Pierre Bourdieu, Distinction: A Social Critique of the Judgment of Taste, Routledge, London, 1984, p. 359. Bourdieu's concept has since been modified and adopted in a wide number of scholarly debates and fields. For overviews of its applicability to and position within media and creative industries scholarship, see Jennifer Smith Maguire and Julian Matthews, 'Cultural Intermediaries and the Media', Sociology Compass, vol. 4, no. 7, 
2010, pp. 405-16 and David Hesmondhalgh, 'Bourdieu, the Media and Cultural Production', Media, Culture \& Society, vol. 28, no. 2, 2006, pp. 211-31.

6 Twenty music writers at different points in their career were surveyed in late 2010. Data was gathered primarily through questionnaires and, in a few cases, face-to-face or telephone interviews. Transcripts are held on secure Swinburne University servers. Pseudonyms have been used through this article and all unattributed quotes are from these interviews. See also Ramon Lobato and Lawson Fletcher, 'Prestige and Professionalisation at the Margins of the Journalistic Field: The Case of Music Writers' in Amateur Media: Social, Cultural and Legal Perspectives, ed. Dan Hunter, Ramon Lobato, Megan Richardson and Julian Thomas, Routledge, London and New York, 2012, pp. 111-24.

7 Through terms like 'passion' and 'obsession', it seems Anna subscribes to what, elsewhere, we have termed the 'romantic model of rock criticism as vocation', in which dedication to the craft apparently outstrips economic considerations. See Lobato and Fletcher, 'Prestige and Professionalization', pp. 114-16.

${ }^{8}$ Just as there are many different kinds of music writer, there are many different kinds of bloggersome are dedicated to regular updates of local music and news, others use blogs as proxy locations for expanding MP3 collections, while some produce expansive, long-form criticism. These distinctions are explored further in Lobato and Fletcher, 'Prestige and Professionalisation'. See also Beatrice Jetto, 'Music Blogs, Music Scenes, Sub-Cultural Capital: Emerging Practices in Music Blogs', paper presented at Cybercultures: Exploring Critical Issues conference, Salzburg, Austria, 2010.

${ }^{9}$ Gestur Guðmundsson, Ulf Lindberg, Morten Michelsen and Hans Weisenthaunet, 'Brit Crit: Turning Points in British Rock Criticism, 1960-1990' in Pop Music and the Press, ed. Steve Jones, Temple University Press, Philadelphia, 2002, p. 60.

10 One can also view this relinquishment as an implicit affirmation of music writing's version of journalistic objectivity, insofar as a dispassionate relationship to subject matter is seen by some writers as an ethical requirement. In her study of US critics' perceptions of their cultural authority, Klein similarly notes many writers argued they 'should have a breadth of knowledge, and should be able to make studied judgements regardless of personal preferences'. Bethany Klein, 'Dancing About Architecture: Popular Music Criticism and the Negotiation of Authority', Popular Communication: The International Journal of Media and Culture, vol. 3, no. 1, 2005, p. 5.

11 Bourdieu, Distinction, p. 120.

$12 \mathrm{Nick}$, like other editors from niche publications we interviewed, even rejects the assumption that quality of copy is positively correlated to pay rates: 'I think the writers for Mess+Noise wouldn't write any better if they were getting $\$ 500$ a piece instead of $\$ 60$. I think the reason they write for Mess + Noise is because they're passionate about it and they get the space to write about things no one else would give them.'

13 See Melissa Gregg, Work's Intimacy, Polity Press, London, 2011; Andrew Ross, No-Collar: The Humane Workplace and its Hidden Costs, Temple University Press, Philadelphia, 2003. 
14 Caroline Hamilton, 'The Exposure Economy', Overland, no. 202, 2011,

$<$ http://overland.org.au/previous-issues/issue-202/essay-caroline-hamilton/>.

15 This rapidly deformalising and splintering music industry can lead to confusion for writers working at the peak speeds of new music and media. Pam, editor of a national glossy music magazine, mentioned that she gets more and more pitches from writers who simply do not understand the different temporalities of print versus online music media ('For example, it's December now and I'm commissioning the April issue-so an article on how the ARIAs [held in November] suck would work better as a series of tweets'). One writer mentioned that the niche artists he covers do not even schedule releases far enough ahead to accommodate the two-to-three-month lead time of the glossies.

16 Many writers have supplemented their income by selling review copies of CDs to second-hand stores, a practice which is widespread but technically illegal and detested by record companies. With the advent of digital delivery this secondary economy is drying up.

17 Keith Negus, Producing Pop: Culture and Conflict in the Popular Music Industry, Arnold, London, 1992, p. 125.

18 On writers as gatekeepers, see Roy Shuker, 'On the Cover of the Rolling Stone: The Music Press', in Roy Shuker, Understanding Popular Music, Routledge, London, 2001, pp. 83-98; Simon Frith, Sound Effects: Youth, Leisure and the Politics of Rock'n'Roll, Pantheon Books, 1981, New York.

19 Don McLeese, 'Straddling the Cultural Chasm: The Great Divide between Music Criticism and Popular Consumption', Popular Music and Society, vol. 33, no. 4, 2010, pp. 433-47. One interviewee, Tom, speculated that this situation means writing will increasingly have to operate as an entertaining, semiautonomous cultural artefact that engages readers on its own merits:

I think this idea that really came about probably in the eighties that, I am the writer therefore I have the ultimate opinion of this record, is a bit of a naive thing. So I think writers, to keep an audience, have to change the way they write. They have to be entertaining, there's so much dry criticism that's boring as bat shit, and hell, I'm responsible for some of it as well. But I think if you want people to keep engaged in a review-especially keeping in mind that they don't have to read a review in order to get a sense of a record, they can download it for free-you have to ask yourself, why are people going to read this?

He cited Andy Ramadge's long-form gonzo piece, The World According to Gaz-on Australian musician Gareth Liddiard-as an example of this kind of work which unfortunately is increasingly harder to write due to the promotional constrains on writing, or 'because you only get fifteen minutes with bands these days'. See Andrew Ramadge, The World According to Gaz, 2010,

$<$ http://www.theworldaccordingtogaz.com/>.

${ }^{20}$ Maguire and Matthews, p. 408. Anna, for instance, appeared genuinely flattered and incredulous when a reader told her: 'I didn't like that band but your article made me think a bit more about them.' 21 Pierre Bourdieu, 'The Market of Symbolic Goods', Poetics, vol. 14, 1985, p. 15. 
22 Studies of music writer demographics in other countries have found similar instances of gender disparity, see Robert 0. Wyatt and Geoffrey P. Hull, 'The Music Critic in the American Press: A Nationwide Survey of Newspapers and Magazines', Mass Communication Review, vol. 17, no. 3, 1989, p. 38. For further discussion of gender politics in music criticism, see Kembrew McLeod, “'One and a Half Stars": A Critique of Rock Criticism in North America', Popular Music, vol. 20, no. 1, 2001, pp. 47-60; Helen Davies, 'All Rock and Roll Is Homosocial: The Representation of Women in the British Rock Music Press', Popular Music, vol. 20, no. 3, 2001, pp. 301-19.

${ }^{23}$ Keith Negus, 'The Work of Cultural Intermediaries and the Enduring Distance Between Production and Consumption', Cultural Studies, vol. 16, 2002, p. 511.

${ }^{24}$ Crawford has speculated on whether the decline of the physical music publication office as a 'social nexus' for writers, which operates on similar forms of spatialised exclusion, and the rise of online 'outworkers', where contact with editors and writers is almost solely through email, might provide a situation in which more women can participate. Anwyn Crawford, 'Working for the Man', Popular Demand, 28 February 2010, <http://populardemand.wordpress.com/2010/02/07/working-for-theman/>. The prevalence of extreme forms of misogyny and insult culture online-as female bloggers sharing stories of the often highly violent and threatening abuse directed at them via the \#mencallmethings Twitter hashtag has recently demonstrated-would suggest that marginalisation based on gender is not so easy to escape. For more on \#mencallmethings, see Karalee Evans, 'Men Call Me Things: It's Not as Romantic as It Sounds', ABC The Drum Unleashed, 11 November 2011, <http://www.abc.net.au/unleashed/3659712.html>.

25 McLeod, p. 48.

26 In this sense, music writing is similar to the community of record collectors observed by Straw, a homosocial environment characterised by slavish devotion to a shared, specialised knowledge that guards against the encroachment of 'outsiders'. Will Straw, 'Sizing up Record Collections: Gender and Connoisseurship in Rock Music Culture' in Sexing the Groove: Popular Music and Gender, ed. Sheila Whiteley, Routledge, London, 1997, pp. 3-16. See also Davies; Athena Elafros, “'No Beauty Tips or Guilt Trips": Rockrgrl, Rock, and Representation', Popular Music and Society, vol. 33, no. 4, 2010, pp. 487-99; Anwyn Crawford, 'Girls Just Wanna Have Fun?', Loops, vol. 1, 2009, pp. 195-203.

${ }^{27}$ Sean Nixon and Ben Crewe, 'Pleasure at Work? Gender Consumption and Work-Based Identities in the Creative Industries', Consumption, Markets and Culture, vol. 7, no. 2, 2004, pp. 129-47; Angela McRobbie, 'Clubs to Companies: Notes on the Decline of Political Culture in Speeded up Creative Worlds', Cultural Studies, vol. 16, 2002, pp. 516-31.

${ }^{28}$ Negus, 'The Work of Cultural Intermediaries', p. 513.

${ }^{29}$ Lobato and Fletcher, 'Prestige and Professionalization'.

30 Andy Bennett and Richard A. Peterson, 'Introducing Music Scenes', in Music Scenes: Local, Translocal and Virtual, Vanderbilt University Press, Nashville, 2004, p. 1. It is important to note that scenes do not only take place within localised geographies-indeed, music writers can be central to the constitution 
of what Bennett and Peterson call 'trans-local' or 'virtual' scenes of otherwise dispersed participants who share a similar aesthetic sensibility. The blog Rose Quartz is a good example here-with writers across Australia, New Zealand and the United States, it has played a key role in substantiating bedroom-producer genres such as chillwave and witch house through collecting otherwise isolated examples of these sounds and curating them on their blogs. It has also helped establish a cultural grammar and critical mass for such genres. Blogger Richard says that he also feels Rose Quartz plays a minor economic role: 'I feel our role aids small labels that release cassettes or even self-releasing artists, providing direct links to Bandcamp [an online music store and promotional platform for independent artists] or other ways to purchase material that would otherwise only be visible on a band's MySpace or something.'

${ }^{31}$ Adam Brown, Justin O'Connor and Sara Cohen, 'Local Music Policies Within a Global Music Industry: Cultural Quarters in Manchester and Sheffield', Geoforum, vol. 31, no. 4, 2000, pp. 437-51.

32 Bennett and Peterson, p. 5. See also Richard Smith and Tim Maughan, 'Youth Culture and the Making of the Post-Fordist Economy: Dance Music in Contemporary Britain', occasional paper, Department of Social Policy and Social Science, Royal Holloway, University of London, London, 1997.

33 Sarah Thornton, Club Cultures: Music, Media and Subcultural Capital, Polity Press, Cambridge, 1995, p. 151. 